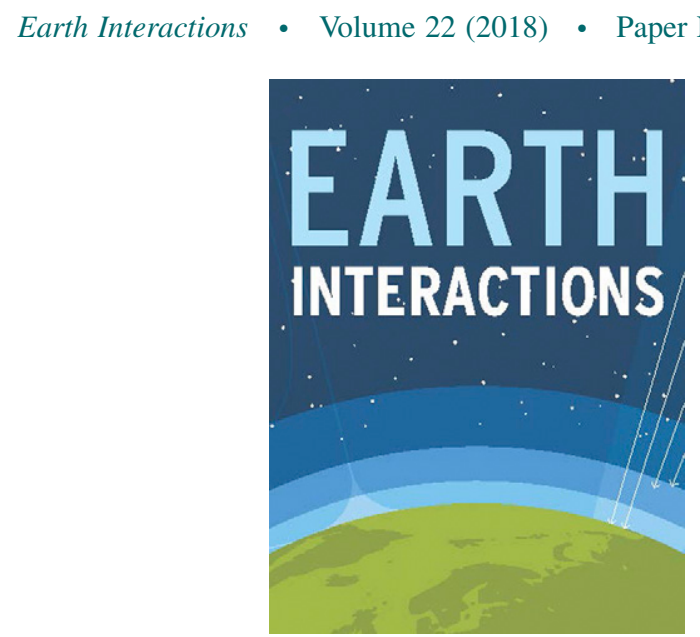

(C) 2018 American Meteorological Society. For information regarding reuse of this content and general copyright information, consult the AMS Copyright Policy (www.ametsoc.org/PUBSReuseLicenses).

\title{
Evaluation of TOPMODEL-Based Land Surface-Atmosphere Transfer Scheme (TOPLATS) through a Soil Moisture Simulation
}

\section{Xiaolei Fu, ${ }^{\text {a,b,c,g }}$ Lifeng Luo, ${ }^{\text {b,d,g }}$ Ming Pan, ${ }^{\mathrm{e}}$ Zhongbo Yu, ${ }^{\mathrm{f}}$ Ying Tang, ${ }^{\mathrm{b}}$ and Yongjian Ding ${ }^{\mathrm{c}}$}

${ }^{a}$ College of Civil Engineering, Fuzhou University, Fuzhou, China

${ }^{\mathrm{b}}$ Department of Geography, Environment, and Spatial Sciences, Michigan State University, East Lansing, Michigan

${ }^{c}$ State Key Laboratory of Cryospheric Science, Northwest Institute of Eco-Environment and Resources, Chinese Academy of Sciences, Lanzhou, China

${ }^{\mathrm{d}}$ Center for Global Change and Earth Observations, Michigan State University, East Lansing, Michigan

e Department of Civil and Environmental Engineering, Princeton University, Princeton, New Jersey

${ }^{\mathrm{f}}$ State Key Laboratory of Hydrology-Water Resources and Hydraulic Engineering, Hohai University, Nanjing, China

Received 13 December 2017; in final form 7 May 2018

ABSTRACT: Better quantification of the spatiotemporal distribution of soil moisture across different spatial scales contributes significantly to the understanding of land surface processes on the Earth as an integrated system. While observational data for root-zone soil moisture (RZSM) often

\footnotetext{
g Corresponding authors: Xiaolei Fu, fuxiaolei518@163.com; Lifeng Luo, lluo@msu.edu
} 
Earth Interactions - Volume 22 (2018) - Paper No. 15 • Page 2

have sparse spatial coverage, model-simulated soil moisture may provide a useful alternative. TOPMODEL-Based Land Surface-Atmosphere Transfer Scheme (TOPLATS) has been widely studied and actively modified in recent years, while a detailed regional application with evaluation currently is still lacking. Thus, TOPLATS was used to generate high-resolution (30 arc s) RZSM based on coarse-scale $\left(0.125^{\circ}\right)$ forcing data over part of the Arkansas-Red River basin. First, the simulated RZSM was resampled to coarse scale to compare with the results of Mosaic, Noah, and VIC from NLDAS. Second, TOPLATS performance was assessed based on the spatial absolute difference among the models. The comparison shows that TOPLATS performance is similar to VIC, but different from Mosaic and Noah. Last, the simulated RZSM was compared with in situ observations of 16 stations in the study area. The results suggest that the simulated spatial distribution of RZSM is largely consistent with the distribution of topographic index (TI) in most instances, as topography was traditionally considered a major, but not the only, factor in horizontal redistribution of soil moisture. In addition, the finer-resolution RZSM can reflect the in situ soil moisture change at most local sites to a certain degree. The evaluation confirms that TOPLATS is a useful tool to estimate high-resolution soil moisture and has great potential to provide regional soil moisture estimates.

KEYWORDS: Hydrology; Soil moisture; Hydrologic models; Land surface model

\section{Introduction}

Soil moisture is not only an important variable for meteorology, hydrology, and agriculture applications (Heathman et al. 2003), but it is also the key factor in land-atmosphere interactions (Yu et al. 2014), primarily due to its control of water and energy fluxes in land surface (Daly and Porporato 2005; Qin et al. 2009; Al-Hamdan and Cruise 2010; Li et al. 2010). It affects not only the partitioning of energy between sensible and latent heat in the atmosphere (Koster et al. 2004), but also the water partitioning between infiltration and runoff at the land surface (Silberstein et al. 1999; Western and Blöschl 1999; Koster et al. 2003). In agriculture, water availability in the soil has a significant role in the crop production, irrigation scheduling, and water resource management (Hanson et al. 1998; Ma et al. 1998; Lü et al. 2011a,b; Fu et al. 2014). Despite the importance of soil moisture, the analyses on this topic are primarily limited to in situ or vertical soil moisture distribution during the past several decades based on local observation or simulation.

For example, the local soil-vegetation-atmosphere transfer scheme (SVATS) (Famiglietti 1992) divides the soil column into two layers: (i) the upper, more active root zone and (ii) the lower, less active transmission zone. In this model, the purpose is to simulate the horizontal water and energy fluxes and the vertical recharge to the water table. The Biosphere-Atmosphere Transfer Scheme (BATS) (Dickinson et al. 1993) and the Simple Biosphere Model (SiB) (Sellers et al. 1986) divide the vertical soil column into several layers. Both of their parameterizations are the simplified vertical process physics and the statistical horizontal process of runoff and energy. Additionally, for analyzing soil moisture distribution at the regional scale, common alternatives, including hydrologic models and coupled climate models (Njoku et al. 2003; Bindlish et al. 2003; Kerr et al. 2010; Entekhabi et al. 2010; Pan et al. 2014; Lettenmaier et al. 2015), are often preferred for their reliability. 
Earth Interactions - Volume 22 (2018) • Paper No. 15 • Page 3

The Xinanjiang model can produce average soil moisture over a region, while its suitability is limited to humid and semihumid areas and is not as impressive for arid and semiarid areas (Zhao et al. 1980; Zhao 1992; Jayawardena and Zhou 2000; Cheng et al. 2002; Ju et al. 2009; Li et al. 2009). On the other hand, the TOPMODEL (topography-based hydrologic model) (Kirkby 1976; Beven and Kirkby 1979; Beven and Wood 1983) can also simulate the regional soil moisture but is usually constrained to the catchments up to $500 \mathrm{~km}^{2}$ (Beven et al. 1984). Furthermore, the Variable Infiltration Capacity (VIC) model, a macroscale hydrological model (Liang et al. 1994, 1996), can simulate the soil moisture distribution for larger regions. However, the coarse-resolution (e.g., $0.125^{\circ}$ ) output generally does not satisfy the finer-resolution requirement of soil moisture distribution (Beyene et al. 2010; Mishra et al. 2010; Cuo et al. 2011; Ni-Meister and Gao 2011; Shukla et al. 2011).

Famiglietti and Wood (1994a) presented a multiscale hydrologic model, the TOPMODEL-Based Land Surface-Atmosphere Transfer Scheme (TOPLATS), which is used to account for the lateral subsurface water redistribution based on the soil topography (Beven and Kirkby 1979; Sivapalan et al. 1987). The model can be used not only at local sites but also at catchments and macroscales per its principle. This model was applied at the King Creek catchment, which covers an area of $11.7 \mathrm{~km}^{2}$, as part of the First International Satellite Land Surface Climatology Project (ISLSCP) Field Experiment (FIFE), which showed good results at the five measured stations (Famiglietti and Wood 1994b). Famiglietti and Wood (1995) used this model to explore how spatial variability and scale affect the spatially averaged evapotranspiration in the King Creek catchment and found that the model parameters and inputs may play a key role in the evapotranspiration rate calculation when the catchment area is smaller than a certain threshold. The study also suggested that the statistical distribution functions can represent the dominant spatial patterns when the study area is sufficiently large. The TOPLATS has also been applied to understand the interactions between the boreal forest and the atmosphere (Pauwels and Wood 1999). Peters-Lidard et al. (1997) modified the TOPLATS model due to the deficiencies of some properties (e.g., ground heat flux, soil evaporation, or transpiration) to reduce the prediction errors, which are sensitive to the atmospheric boundary layer.

Even though the TOPLATS model has been widely studied and actively modified in previous studies, a detailed regional application with evaluation is still lacking, in particular its ability to simulate soil moisture distribution at high spatial resolutions. In the current study, the TOPLATS model is applied to river catchments over part of the Arkansas-Red River basin in the United States as an example, in hopes of estimating finer soil moisture distribution based on the coarse-resolution atmosphere forcing data. An evaluation of the simulated results is performed against simulations from several other state-of-the-art land surface models (Mosaic, Noah, and VIC) and in situ observations to examine the performance of the TOPLATS.

\section{Study area and data description}

The study area (Figure 1) covers part of the Arkansas-Red River basin, and the area is over the Southern Great Plains (SGP), where land-atmosphere interaction is considered strong, which makes soil moisture information more useful for weather and climate predictions (Koster et al. 2004). The study area is located in Oklahoma, 
Earth Interactions - Volume 22 (2018) • Paper No. 15 • Page 4

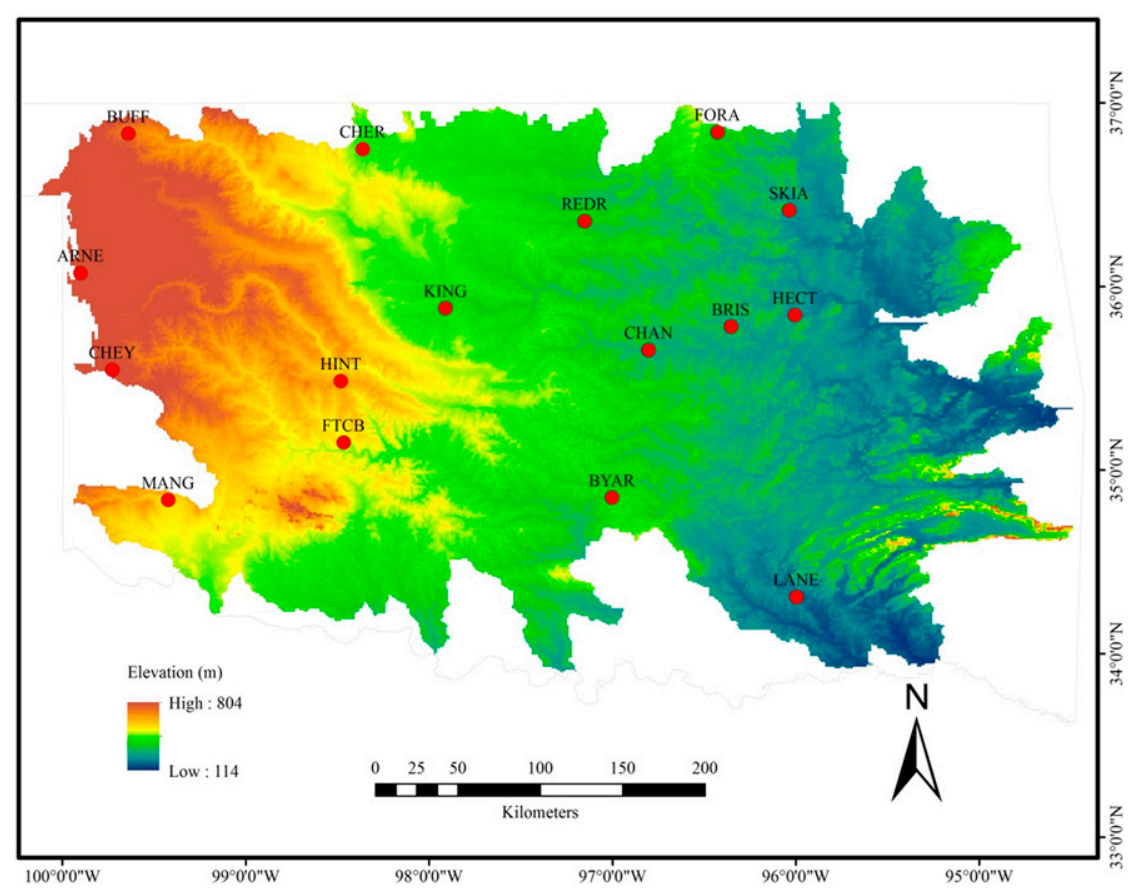

Figure 1. The study area and 16 Oklahoma Mesonet sites in use.

with gradually decreasing elevation from northwest to southeast. Figure 2 shows the distribution of soil topographic index (TI) of the study area calculated at 30 arc s. The soil topographic index formulation described in Beven (1986) indicates that the larger values of TI correspond to the smaller slope of the soil surface, where higher soil moisture content can be found. Precipitation and air temperature decrease from east to west as elevation increases, with averaging annual temperature at $17^{\circ} \mathrm{C}$ and rainfall as high as $1420 \mathrm{~mm}$ in the southeast, and average annual temperature at $14^{\circ} \mathrm{C}$ and annual rainfall under $430 \mathrm{~mm}$ in the west. Vegetation gradually varies from grasslands to woodlands and to forests following the slope.

Over 100 Oklahoma Mesonet stations across the study area have soil moisture observations. As shown in Figure 1, 16 measurement sites with high-quality observations are selected to assess the performance of the model. The observed soil moisture data for the study region are obtained from the Earth Observing Laboratory (EOL) website (http://data.eol.ucar.edu/). The observed soil moisture data are from 2 January to 31 December 2003 in layers at 5-, 25-, and 60-cm depths and are used to calculate the weighted averaged soil moisture [hereafter referred to as observed root-zone soil moisture (RZSM)].

\subsection{Soil parameters}

The soil parameter values of saturated hydraulic conductivity $\left(K_{s}\right)$, saturated soil moisture $\left(\theta_{s}\right)$, residual soil moisture $\left(\theta_{r}\right)$, air entry suction head $\left(\psi_{c}\right)$, and pore size distribution index $(B)$, which depend on the soil type, are obtained from Famiglietti 


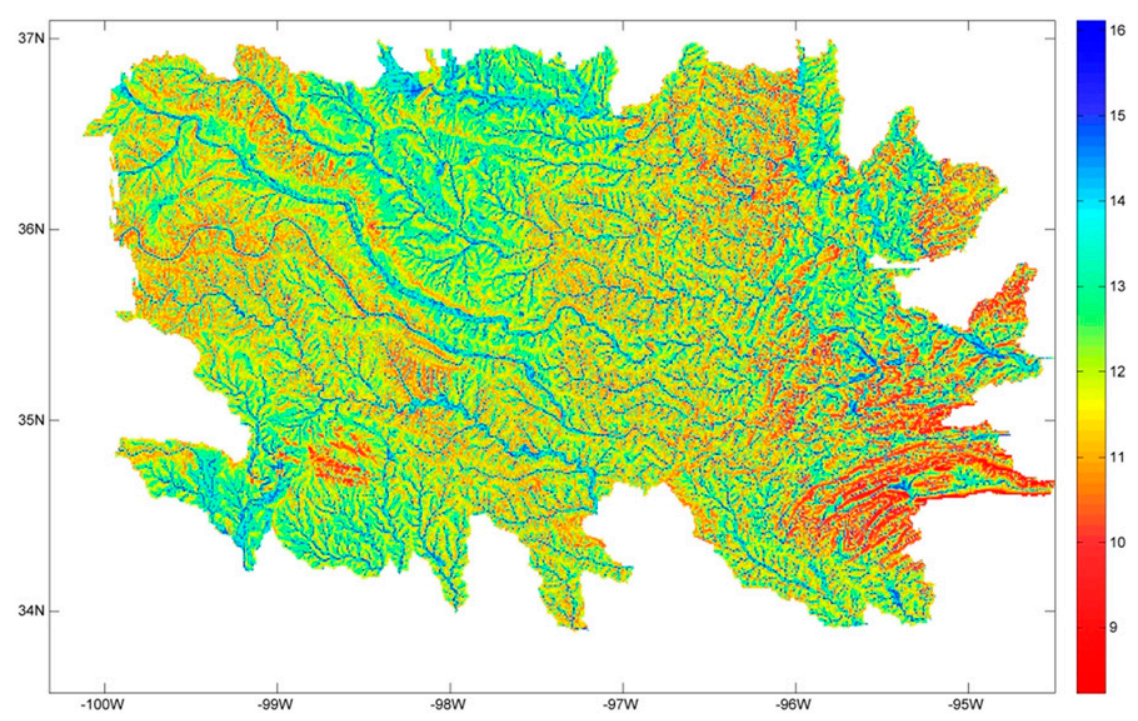

Figure 2. Soil TI calculated at 30-arc-s resolution.

and Wood (1994b). Additionally, other soil parameter values are listed in Table 1. As mentioned earlier, the observed soil moisture in the three layers $(5,25$, and $60 \mathrm{~cm})$ is used to calculate the observed RZSM, and the root-zone depth is assumed to be $1 \mathrm{~m}$.

\subsection{Vegetation parameters}

Some vegetation parameters, such as wet vegetation albedo, take a fixed value for the entire study region, which can be found in Table 1. On the other hand, parameters like leaf area index (LAI), which vary spatially, are not shown. The LAI is from Boston University (http://sites.bu.edu/cliveg/) (Zhu et al. 2013).

\subsection{Meteorological forcing data}

The meteorological forcing comes from the North American Land Data Assimilation System (NLDAS) (http://ldas.gsfc.nasa.gov/nldas/), which includes 11 meteorological variables (Xia et al. 2012; Mitchell et al. 2004). Seven are selected to force the TOPLATS model, namely, downward longwave radiation $\left(\mathrm{W} \mathrm{m}^{-2}\right)$, pressure $(\mathrm{hPa})$, relative humidity $(\%)$, downward shortwave radiation $\left(\mathrm{W} \mathrm{m}^{-2}\right)$, air temperature $\left({ }^{\circ} \mathrm{C}\right)$, wind speed $\left(\mathrm{m} \mathrm{s}^{-1}\right)$, and precipitation $\left(\mathrm{m} \mathrm{s}^{-1}\right)$. Cosgrove et al. (2003) pointed out that 1-yr spinup is sufficient for 1-yr simulation at this particular area of warm temperature (no snow) and frequent precipitation (fast soil moisture dynamics). Thus, the meteorological data of the years 2002 and 2003 are collected to run the model. The data from 1 January 2002 to 1 January 2003 are used to spin up the model, while the rest of the data are used to simulate RZSM. The resolution of the meteorological data is $0.125^{\circ}$, and the range of the forcing variables from 1 January 2002 to 31 December 2003 is listed in Table 2. For running the model, 
Earth Interactions - Volume 22 (2018) • Paper No. 15 • Page 6

Table 1. The values of inputted parameters for the TOPLATS model.

\begin{tabular}{|c|c|c|c|}
\hline Parameter & Variable & Value & Source \\
\hline \multicolumn{4}{|c|}{ Soil parameters } \\
\hline Quartz content & $q$ & 0.1 & Peters-Lidard et al. (1997) \\
\hline Dry soil heat capacity $\left(\mathrm{J} \mathrm{K}^{-1} \mathrm{~kg}^{-1}\right)$ & $C_{s}$ & $1.3 \times 106$ & Peters-Lidard et al. (1997) \\
\hline Root-zone depth (m) & $z_{\mathrm{rz}}$ & 1 & \\
\hline Wilting soil moisture & $\theta_{w}$ & 0.11 & Peters-Lidard et al. (1997) \\
\hline Field capacity & $\theta_{\text {cap }}$ & 0.38 & Peters-Lidard et al. (1997) \\
\hline \multicolumn{4}{|c|}{ Vegetation parameters } \\
\hline Minimum stomatal resistance $\left(\mathrm{sm}^{-1}\right)$ & $r_{\mathrm{stmin}}$ & 80 & $\begin{array}{l}\text { Peters-Lidard et al. (1997); } \\
\text { Pauwels and Wood (1999) }\end{array}$ \\
\hline Maximum stomatal resistance $\left(\mathrm{sm}^{-1}\right)$ & $r_{\text {stmax }}$ & 5000 & Peters-Lidard et al. (1997) \\
\hline $\mathrm{F} 1$ parameter $2\left(\mathrm{Wm}^{-1}\right)$ & $R_{\mathrm{pl}}$ & 100 & Peters-Lidard et al. (1997) \\
\hline $\mathrm{F} 2$ parameter 1 & $\beta$ & 0.0002 & Peters-Lidard et al. (1997) \\
\hline $\mathrm{F} 3$ parameter $1\left(\mathrm{~K}^{-2}\right)$ & $B 1$ & 0.00016 & Peters-Lidard et al. (1997) \\
\hline Wet vegetation albedo & $\alpha_{w}$ & 0.25 & Peters-Lidard et al. (1997) \\
\hline Dry vegetation albedo & $\alpha_{d}$ & 0.2 & Peters-Lidard et al. (1997) \\
\hline Emissivity & $\epsilon$ & 1 & Peters-Lidard et al. (1997) \\
\hline Zero plane displacement (m) & $d_{0}$ & 0 & Peters-Lidard et al. (1997) \\
\hline Momentum roughness length $(\mathrm{m})$ & $z_{\mathrm{om}}$ & 0.19 & Peters-Lidard et al. (1997) \\
\hline Scalar roughness length $(\mathrm{m})$ & $z_{\mathrm{oh}}$ & 0.019 & Peters-Lidard et al. (1997) \\
\hline Fractional cover & $f$ & 0.8 & Famiglietti and Wood (1994b) \\
\hline \multicolumn{4}{|c|}{ TOPMODEL parameters } \\
\hline Base flow at saturation $\left(\mathrm{m}^{3} \mathrm{~s}^{-1}\right)$ & $Q_{o}$ & 30 & Esralew and Lewis (2010) \\
\hline Initial average water table depth (m) & $\bar{z}$ & 2.1 & Peters-Lidard et al. (1997) \\
\hline
\end{tabular}

the forcing data $\left(0.125^{\circ}\right)$ were interpolated into each modeling grid (30 arc s) using the inverse-distance-weighted (IDW) method.

\section{Methodology}

\subsection{Model description}

The TOPLATS model includes three scales: local scale, catchment scale, and macroscale. A detailed description of processes at these scales can be found in Famiglietti and Wood (1994a), and a brief introduction is provided here.

\subsubsection{Local scale}

In the TOPLATS model, the local model used is local SVATS, which partitions the land surface into two components: bare soil and vegetation. There are many model variables above the land surface that can be calculated. For example, evaporation and transpiration are calculated for bare soil and vegetation, respectively. Sensible heat flux, infiltration, and surface runoff are also computed for the land surface.

The local model divides the vertical soil into two layers: the root zone, which supplies the soil moisture for the bare soil and vegetation, and the transmission zone, which extends from the top of the capillary fringe to the bottom of the root zone. The capillary fringe is dependent on the water table depth. That is to say, at a 
Earth Interactions - Volume 22 (2018) - Paper No. 15 • Page 7

Table 2. The range of forcing variables from 1 Jan 2002 to 31 Dec 2003 in the study area.

\begin{tabular}{lcccc}
\hline \multicolumn{1}{c}{ Variable } & & Range & Unit \\
\hline Downward longwave radiation & 145.87 & $\sim$ & 506.67 & $\mathrm{~W} \mathrm{~m}^{-2}$ \\
Pressure & 830.18 & $\sim$ & 1027.8 & $\mathrm{hPa}$ \\
Relative humidity & 2.5 & $\sim$ & 100 & $\%$ \\
Downward shortwave radiation & 0 & $\sim$ & 1021 & $\mathrm{~W} \mathrm{~m}^{-2}$ \\
Air temperature & -17.6 & $\sim$ & 44.6 & ${ }^{\circ} \mathrm{C}^{-1}$ \\
Wind speed & 0 & $\sim$ & 16 & $\mathrm{~m} \mathrm{~s}^{-1}$ \\
Precipitation & 0 & $\sim$ & $1.68 \times 10^{-5}$ & $\mathrm{~m} \mathrm{~s}^{-1}$ \\
\hline
\end{tabular}

specific site, the transmission zone may disappear if the water table depth is above the bottom of the root zone. The details of the local SVATS model are described in Famiglietti (1992).

\subsubsection{Catchment scale}

The local SVATS model is aggregated into each catchment based on the resolution of digital elevation model (DEM) using the spatially distributed model formulation. Because the local water table depth is needed as the lower-boundary condition for the SVATS model, the soil TI (Beven 1986) is used to compute and update the catchment-scale pattern of water table depth and to couple water table depth to each grid element at the catchment scale. The same variables as in the local SVATS model are needed at the catchment scale.

\subsubsection{Macroscale}

At the macroscale, a statistical distribution of soil topographic index is applied to aggregate the local SVATS model to the macroscale based on the following two assumptions: (i) subgrid-scale spatial variability controls the grid-scale water and energy balance significantly at root zone, and (ii) a threshold modeling scale has been exceeded at the macroscale. The same topographic index value at different locations implies a similar hydrologic response, which was described by Sivapalan et al. (1987) and Wood et al. (1990). Thus, model grids are grouped into different bins according their topographic index values, and the local SVATS model is solved at each bin.

Originally, the TOPLATS refers to the local SVATS model coupled to the TOPMODEL framework (Beven and Kirkby 1979; Beven 1986; Sivapalan et al. 1987) at the macroscale. In this study, the model including the above three scales is also called the TOPLATS model.

\subsection{Evaluation metrics}

To evaluate the performance of the TOPLATS model, we first resampled the 30 -arc-s-resolution soil moisture from TOPLATS to $0.125^{\circ}$ and compared it with coarse-resolution soil moisture simulated by three state-of-the-art models, namely, Mosaic, Noah, and VIC from NLDAS. The mean absolute difference is used to measure the performance. Then, based on data at the 16 soil moisture observation 
sites, the root-mean-square error (RMSE), mean absolute error (MAE), averaged relative error $(\mathrm{RE})$, and correlation coefficient $(R)$ are calculated to assess its general performance:

$$
\begin{aligned}
\mathrm{RMSE}= & {\left[\frac{1}{n} \sum_{i=1}^{n}\left(X_{\mathrm{pred}, i}-X_{\mathrm{obs}, i}\right)^{2}\right]^{1 / 2}, } \\
\mathrm{ME}= & \frac{\left|\overline{X_{\mathrm{pred}}}-\overline{X_{\mathrm{obs}}}\right|}{\overline{X_{\mathrm{obs}}}}, \frac{1}{n} \sum_{i=1}^{n}\left|X_{\mathrm{pred}, i}-X_{\mathrm{obs}, i}\right|, \\
R= & \frac{\sum_{i=1}^{n}\left(X_{\mathrm{pred}, i}-\overline{X_{\mathrm{pred}}}\right)\left(X_{\mathrm{obs}, i}-\overline{X_{\mathrm{obs}}}\right)}{\sqrt{\sum_{i=1}^{n}\left(X_{\mathrm{pred}, i}-\overline{X_{\mathrm{pred}}}\right)^{2} \sum_{i=1}^{n}\left(X_{\mathrm{obs}, i}-\overline{X_{\mathrm{obs}}}\right)^{2}}},
\end{aligned}
$$

where $\overline{X_{\text {pred }}}=1 / n \sum X_{\text {pred }, i}, \overline{X_{\text {obs }}}=1 / n \sum X_{\mathrm{obs}, i}, X_{\text {pred }, i}$ is the simulated RZSM at time $i$; $X_{\mathrm{obs}, i}$ is the observed RZSM at time $i$; and $n$ is total number of time steps.

\section{Resullts}

As discussed earlier, the atmosphere forcing data, including downward longwave radiation, pressure, relative humidity, downward shortwave radiation, air temperature, wind speed, and precipitation, were collected from 1 January 2002 to 31 December 2003. The data were divided into two parts: the first 366 days (1 January 2002 to 1 January 2003) were used to spin up the model, and the remaining 364 days (consistent to the soil moisture observation time) were used for simulation.

Figure 3 shows the mean annual simulated RZSM, which is simply the average of the 364 days in 2003. Soil moisture content in the midnorth and southwest of the region is higher than other areas and lower in the northwest. Figure 2 shows that the larger TI exists in the midnorthern and southwestern regions, and smaller TI is in the northwest, but smallest TI exists in the southeast. Comparing the spatial distribution of simulated RZSM and TI, we see that the distribution of RZSM is consistent with TI in the western and central parts of the region but not in the eastern part, especially in the southeast. The lowest TI exists in the southeastern region, but the smallest RZSM is not in the same area. The comparison suggests that TI is a major influencing factor for RZSM distribution and infers that the larger yearly average RZSM relates to the larger TI generally. Additionally, based on the topography, TI is lowest in the southeast, which is the downstream area with more runoff and generally covered by lots of plants, which may result in a higher RZSM. 
Earth Interactions - Volume 22 (2018) • Paper No. 15 • Page 9

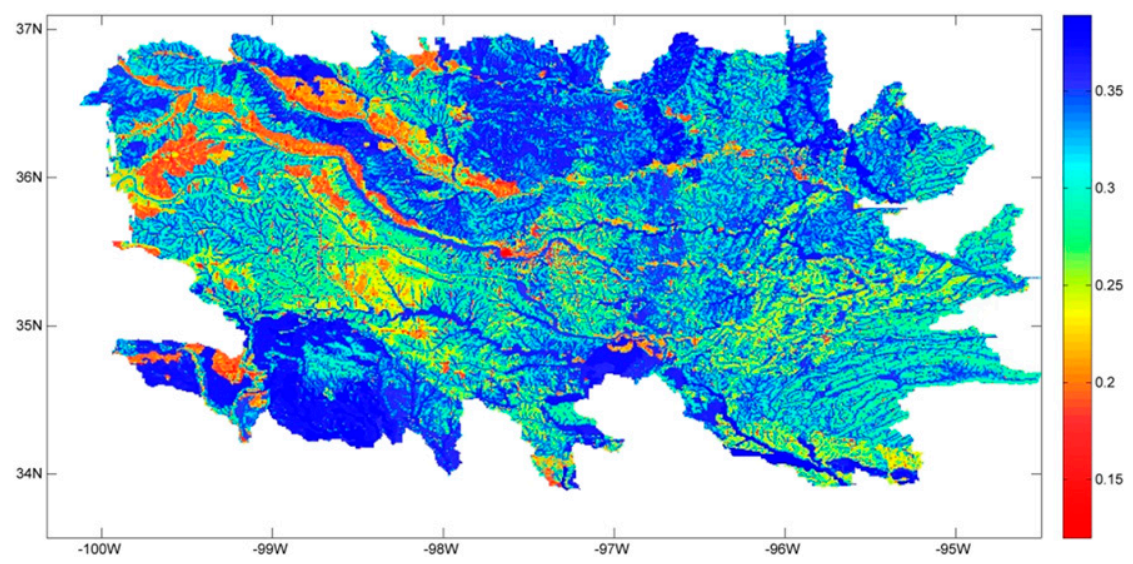

Figure 3. The simulated mean annual RZSM content $\left(\mathrm{m}^{3} \mathrm{~m}^{-3}\right)$ in 2003 at 30 -arc-s resolution.

As there is no large-scale soil moisture observation available to validate the TOPLATS model results, the soil moisture estimates from land surface models in NLDAS are used here as a proxy to evaluate whether the TOPLATS results are reliable at a certain degree, as NLDAS models results are often acceptable in many cases. Thus, we first compare the spatial distribution (hereinafter called distribution) of simulated RZSM by TOPLATS with the results of Mosaic, Noah, and VIC obtained from NLDAS; for local performance, we then compare the 16 soil moisture observation sites' simulated and observed results.

The resolution of RZSM simulated by TOPLATS is 30 arc $\mathrm{s}$, but it is $0.125^{\circ}$ for Mosaic, Noah, and VIC. Thus, the simulated RZSM of TOPLATS was resampled to $0.125^{\circ}$ for comparison. The resampled results are shown in Figure 4e. Figures $4 a-c$ show the RZSM distribution of Mosaic, Noah, and VIC, respectively, and Figure 4d shows the mean (MEAN) RZSM of Mosaic, Noah, and VIC.

In Figure 4, the RZSM pattern of TOPLATS is similar to that of Mosaic, Noah, VIC, and MEAN. However, the soil moisture content of TOPLATS is quite different, compared to that of Mosaic, Noah, and MEAN; however, when compared to VIC, TOPLATS is similar. Meanwhile, the soil moisture content of VIC is significantly different from that of Mosaic, Noah, and MEAN. Such similarities and differences are also shown in Table 3, which shows that the annual areal average soil moisture content of TOPLATS is close to that of VIC in this region but has larger error, compared to other models. Lower RZSM content exists in the northwestern part of the study area for all the models. Only VIC and TOPLATS show that the higher RZSM content mainly exists in the midnorthern and southwestern areas. However, there are some differences between TOPLATS and VIC. For example, in the central part of the study domain, the RZSM content of VIC is around $0.3 \mathrm{~m}^{3} \mathrm{~m}^{-3}$, while for TOPLATS, the RZSM content in some grids of this part is more than $0.35 \mathrm{~m}^{3} \mathrm{~m}^{-3}$. Similar results can be found in the southeastern study area.

To show the performance of TOPLATS directly, the mean absolute difference between TOPLATS and other models is plotted in Figure 5. The results suggest that 

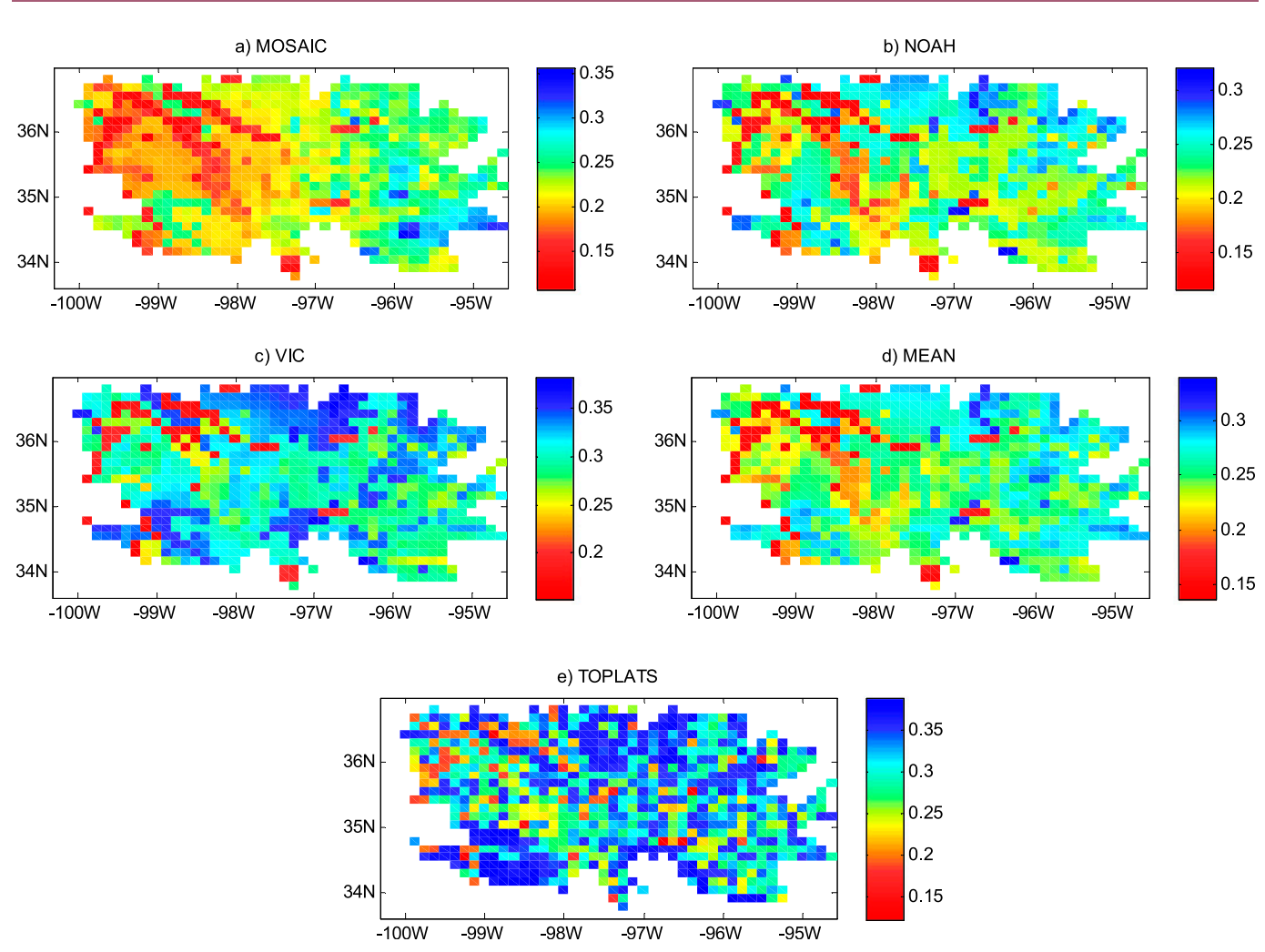

Figure 4. RZSM $\left(\mathrm{m}^{3} \mathrm{~m}^{-3}\right)$ from different models at $0.125^{\circ}$ resolution.

the mean absolute difference between VIC and TOPLATS in the majority of the area (about $2 / 3$ area) is smaller than $0.05 \mathrm{~m}^{3} \mathrm{~m}^{-3}$, and in only a few grids is the mean absolute difference larger than $0.1 \mathrm{~m}^{3} \mathrm{~m}^{-3}$. But between TOPLATS and Mosaic, Noah, and MEAN, the fraction of the grids in which the mean absolute difference is smaller than $0.05 \mathrm{~m}^{3} \mathrm{~m}^{-3}$ is less than $50 \%$.

Figure 6 shows the mean absolute difference distribution among the different models from NLDAS. In this figure, the mean absolute difference between Mosaic and Noah in the majority of the area (almost 90\% area) is smaller than $0.05 \mathrm{~m}^{3} \mathrm{~m}^{-3}$, and in only a few grids is the mean absolute difference larger than $0.1 \mathrm{~m}^{3} \mathrm{~m}^{-3}$. But comparing the Mosaic and Noah results with VIC, it can be found clearly that in less than $20 \%$ of the region, the mean absolute difference among Mosaic, Noah, and VIC is smaller than $0.05 \mathrm{~m}^{3} \mathrm{~m}^{-3}$, but in over $50 \%$ of the region, the mean absolute difference among Mosaic, Noah, and VIC is smaller than $0.1 \mathrm{~m}^{3} \mathrm{~m}^{-3}$.

Table 3. The annual areal average soil moisture $\left(\mathrm{m}^{3} \mathrm{~m}^{-3}\right)$ of different models in 2003. "MEAN" denotes the average result of Mosaic, Noah, and VIC.

\begin{tabular}{lcccc}
\hline Mosaic & Noah & VIC & MEAN & TOPLATS \\
\hline 0.2185 & 0.2241 & 0.3013 & 0.2480 & 0.3089 \\
\hline
\end{tabular}



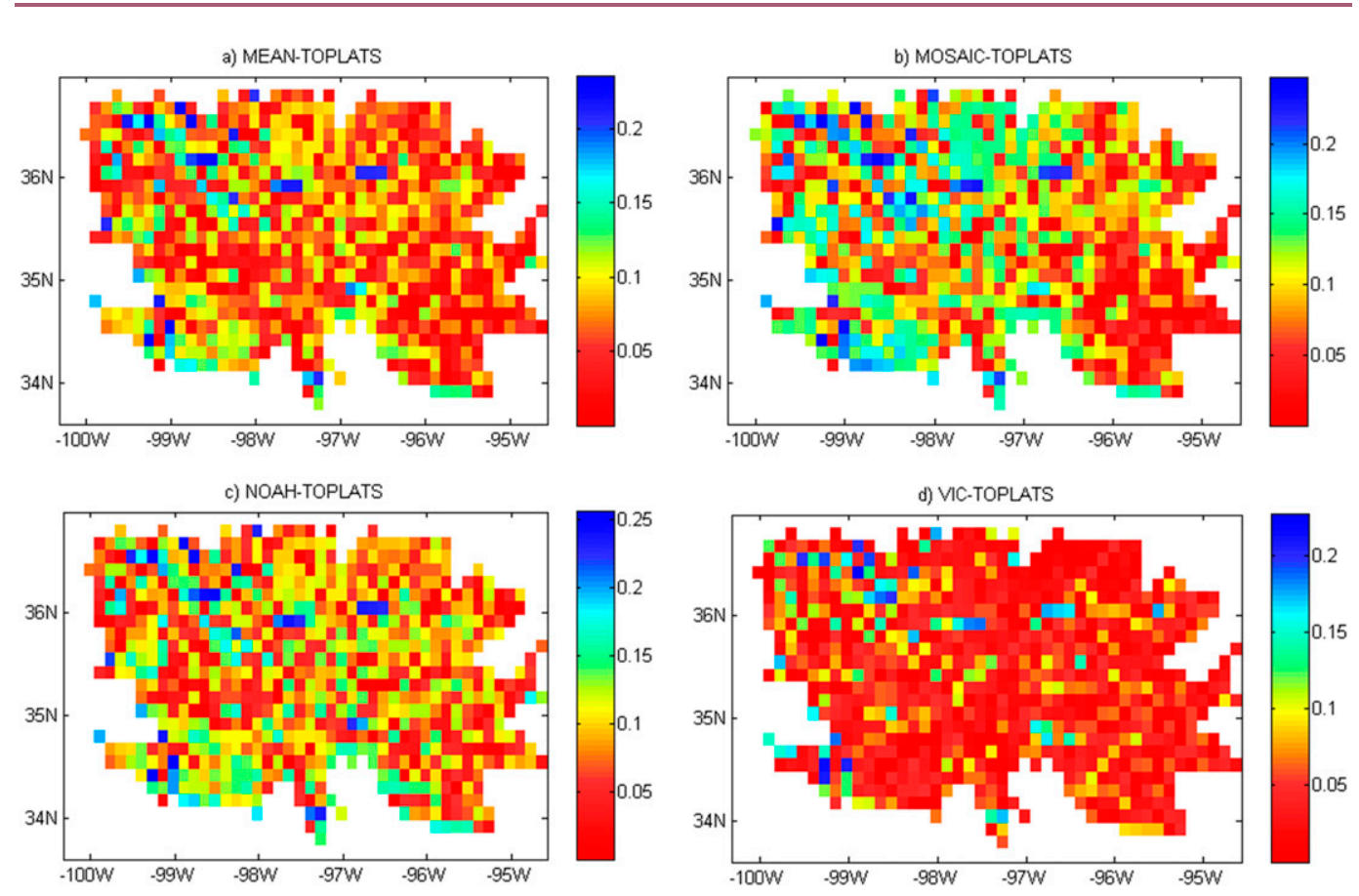

Figure 5. The mean absolute difference $\left(\mathrm{m}^{3} \mathrm{~m}^{-3}\right)$ between TOPLATS and other models at $0.125^{\circ}$ resolution.

Table 4 shows the proportion of land where the mean absolute difference between two models is smaller than $0.05 \mathrm{~m}^{3} \mathrm{~m}^{-3}$. The table confirms that the performance of TOPLATS is similar to VIC, and the Mosaic performance is similar to Noah. Yet, TOPLATS and VIC have a significant discrepancy with Mosaic and Noah.

Figures 4-6 and Table 4 show varied performance among models. If VIC can be used as the reference, the TOPLATS model should be deemed with good performance; on the other hand, the performances of VIC and TOPLATS are not satisfying according to Mosaic and Noah. Additionally, the seasonal and monthly comparison results are not much different than the annual results. Thus, only the annual compared results of the above models are shown.

To further investigate the performance of the TOPLATS model, the observed soil moisture at 16 observation sites in the study area from 2 January to 31 December 2003 was obtained.

Table 5 lists the RMSE, MAE, RE, and $R$ between the simulated RZSM and observed RZSM at each site in the study area for the entire year of 2003. At all 16 sites, the RMSEs are smaller than $0.05 \mathrm{~m}^{3} \mathrm{~m}^{-3}$. Specifically, the RMSE is larger than $0.04 \mathrm{~m}^{3} \mathrm{~m}^{-3}$ at sites BUFF, CHER, KING, and REDR and is smaller than $0.04 \mathrm{~m}^{3} \mathrm{~m}^{-3}$ at the other sites. Correspondingly, the values of MAE at the four sites are larger than $0.03 \mathrm{~m}^{3} \mathrm{~m}^{-3}$, and all are smaller than $0.03 \mathrm{~m}^{3} \mathrm{~m}^{-3}$ at other sites. The values of RE at 12 sites (excluding sites BUFF, CHER, HINT, and LANE) are all smaller than $10 \%$. However, REs at sites BUFF, CHER, HINT, and LANE are smaller than $16 \%$. The correlation coefficient value is between 0.3 and 0.8 at most 

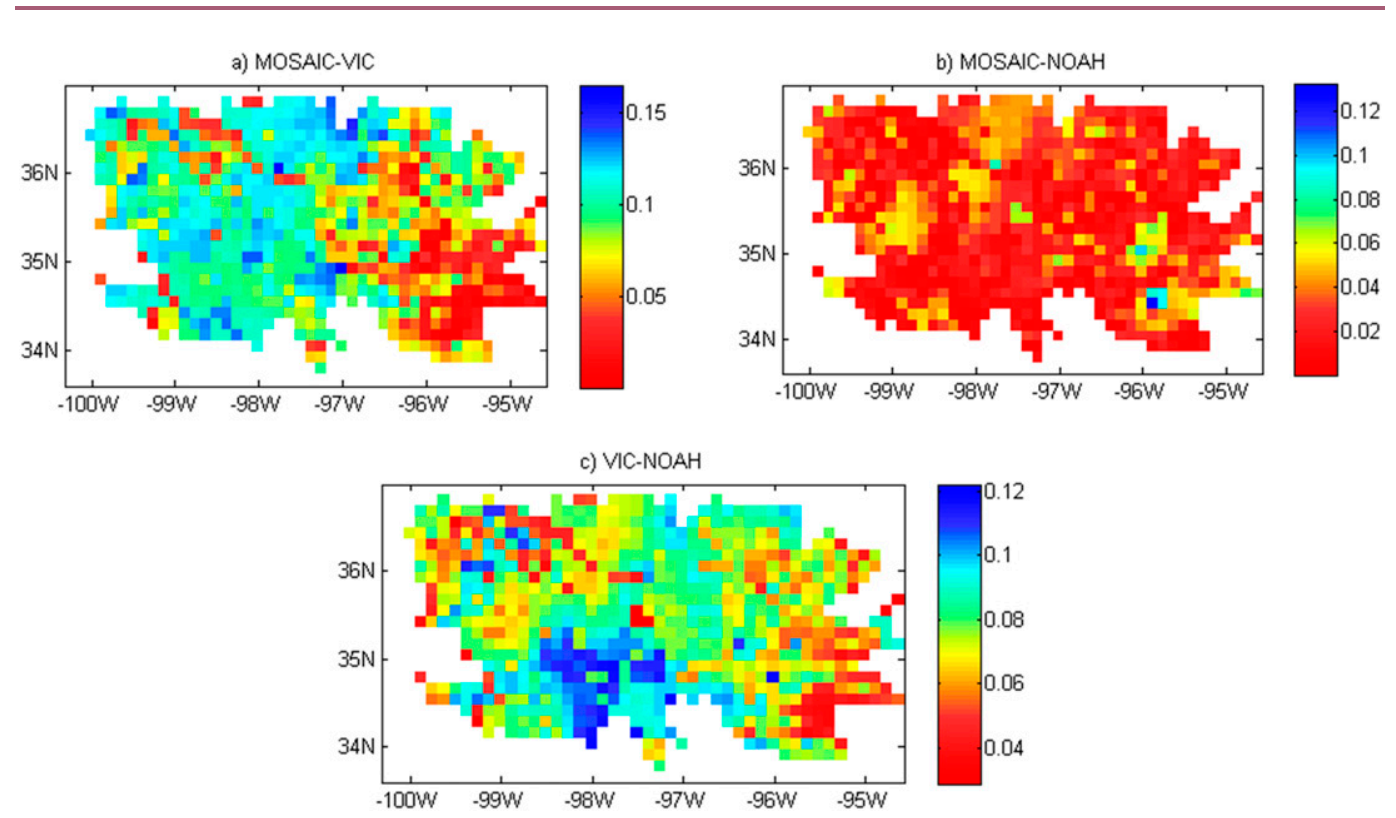

Figure 6. The mean absolute difference $\left(\mathrm{m}^{3} \mathrm{~m}^{-3}\right)$ among the different models' results from NLDAS at $0.125^{\circ}$ resolution.

sites, except at sites CHEY, KINF, SKIA, and HECT. That is to say, the model can well simulate the soil moisture at most sites. For example, at a few stations like BUFF, the RMSE, MAE, RE, and the correlation coefficient at the site are large, which indicates that the simulated RZSM from the TOPLATS model is not performing well, but is in good agreement with observations.

Figure 7 presents the comparison between the simulated RZSM and observed RZSM at the 16 observed sites in the study area in 2003. At most sites, the simulated results can well reflect the temporal dynamics of the RZSM content. However, the simulated RZSM underestimates the RZSM content significantly, compared to the observed RZSM for the first 3 months at sites BUFF and KING. The simulated RZSM overestimates the RZSM content significantly for the entire year of 2003 at site HINT. The possible reasons for underestimation may include that the averaged atmospheric data at $0.125^{\circ}$ are interpolated into each modeling grid (30 arc s). It is possible that the true forcing values at the grid (30 arc s) containing the sites are very different from the interpolated values, which may result in the large error in the sites sometimes.

Table 4. The proportion (\%) of land where the mean absolute difference between two models is smaller than $0.05 \mathrm{~m}^{3} \mathrm{~m}^{-3}$. "MEAN" denotes the average result of Mosaic, Noah, and VIC.

\begin{tabular}{|c|c|c|c|c|}
\hline & VIC & Noah & Mosaic & MEAN \\
\hline TOPLATS & 63.76 & 23.56 & 24.07 & 37.00 \\
\hline VIC & - & 8.45 & 19.72 & - \\
\hline Noah & 8.45 & - & 89.88 & - \\
\hline Mosaic & 19.72 & 89.88 & - & - \\
\hline
\end{tabular}


Earth Interactions - Volume 22 (2018) • Paper No. 15 • Page 13

Table 5 . The yearly RMSE, MAE, RE, and $R$ between the simulated and observed RZSMs at 16 observed sites in 2003.

\begin{tabular}{lcccccccc}
\hline \multicolumn{1}{c}{ Site } & ARNE & BRIS & BUFF & BYAR & CHAN & CHER & CHEY & FORA \\
\hline RMSE $\left(\mathrm{m}^{3} \mathrm{~m}^{-3}\right)$ & 0.0214 & 0.0226 & 0.0401 & 0.0230 & 0.0222 & 0.0402 & 0.0311 & 0.0220 \\
MAE $\left(\mathrm{m}^{3} \mathrm{~m}^{-3}\right)$ & 0.0185 & 0.0198 & 0.0384 & 0.0205 & 0.0167 & 0.0351 & 0.0282 & 0.0151 \\
$\operatorname{RE}(100 \%)$ & 0.0305 & 0.0003 & 0.1073 & 0.0891 & 0.00357 & 0.1589 & 0.0408 & 0.0356 \\
$R$ & 0.3156 & 0.3162 & 0.6502 & 0.7455 & 0.6265 & 0.4555 & 0.0474 & 0.3046 \\
$\quad$ & & & & & & & RAN \\
$\quad$ Site & FTCB & HINT & KING & LANE & MANG & REDR & SKIA & HECT \\
RMSE $\left(\mathrm{m}^{3} \mathrm{~m}^{-3}\right)$ & 0.0165 & 0.0310 & 0.0457 & 0.0386 & 0.0105 & 0.0474 & 0.0312 & 0.0314 \\
MAE $\left(\mathrm{m}^{3} \mathrm{~m}^{-3}\right)$ & 0.0135 & 0.0290 & 0.0401 & 0.0288 & 0.0085 & 0.0393 & 0.0260 & 0.0244 \\
RE $(100 \%)$ & 0.0237 & 0.1540 & 0.0530 & 0.1084 & 0.0207 & 0.0155 & 0.0470 & 0.0874 \\
$R$ & 0.3309 & 0.3203 & 0.2194 & 0.4559 & 0.7801 & 0.5126 & 0.2554 & 0.0638 \\
\hline
\end{tabular}

The soil moisture observations are not error free and, in fact, in several stations, the day-to-day soil moisture variability is probably too small (a flat line in the Figure 7). Noticeably, the simulated RZSM sometimes has a significantly fluctuation, especially on day 243 (31 August 2003). For this specific day, the total precipitation $(\mathrm{mm})$ distribution over the study area is from NLDAS and is presented in Figure 8. The figure shows that the precipitation varies significantly across the study area on that day. The precipitation distribution from NLDAS varies from 1 to $80 \mathrm{~mm}$ in most of the region. Especially in the mideastern part of the region, the total precipitation on that day reaches $80 \mathrm{~mm}$, while in the remaining region, the precipitation is around $1-20 \mathrm{~mm}$. In corollary, the variation of RZSM content should be attributed to precipitation. The significant temporal change of RZSM around day 243 and associated precipitation on that day also suggests that the simulated RZSM is very sensitive to the precipitation. The precipitation data from NLDAS with $0.125^{\circ}$ (Figure 8) show that almost the entire region of the study area is likely to be covered with rainfall on that day. Thus, most modeling grids are covered with the interpolated precipitation on that day. However, the modeling grid contains the soil moisture observed site, and there may be very little or no rainfall at all. As a result, the fluctuation of the observed RZSM is not as significant over some sites (Figure 7).

\section{Discussion}

As many land surface models are developed for working with general circulation models (GCMs), they tend to have good performance at coarse resolutions, but not at finer resolutions. For example, the resolution of Mosaic, Noah, and VIC in NLDAS is $0.125^{\circ}$, and it is $0.25^{\circ}$ or $1.0^{\circ}$ in GLDAS (Rodell et al. 2004). However, hydrology may need finer resolution in many cases (Wood et al. 2011). TOPLATS, the multiscale land surface hydrology model, has its advantage at a finer resolution.

In this study, we take 30-arc-s resolution as an example to run the TOPLATS model and assess its performance in soil moisture simulation. As there are no largescale in situ soil moisture observations available, the soil moisture estimates from Mosaic, Noah, and VIC from NLDAS were used to assess TOPLATS performance. As the resolution in NLDAS is $0.125^{\circ}$, the soil moisture results from TOPLATS were first resampled to $0.125^{\circ}$. Section 4 shows the comparison results, which suggest that different models have different behaviors. Even in NLDAS, the 
Earth Interactions - Volume 22 (2018) - Paper No. 15 • Page 14
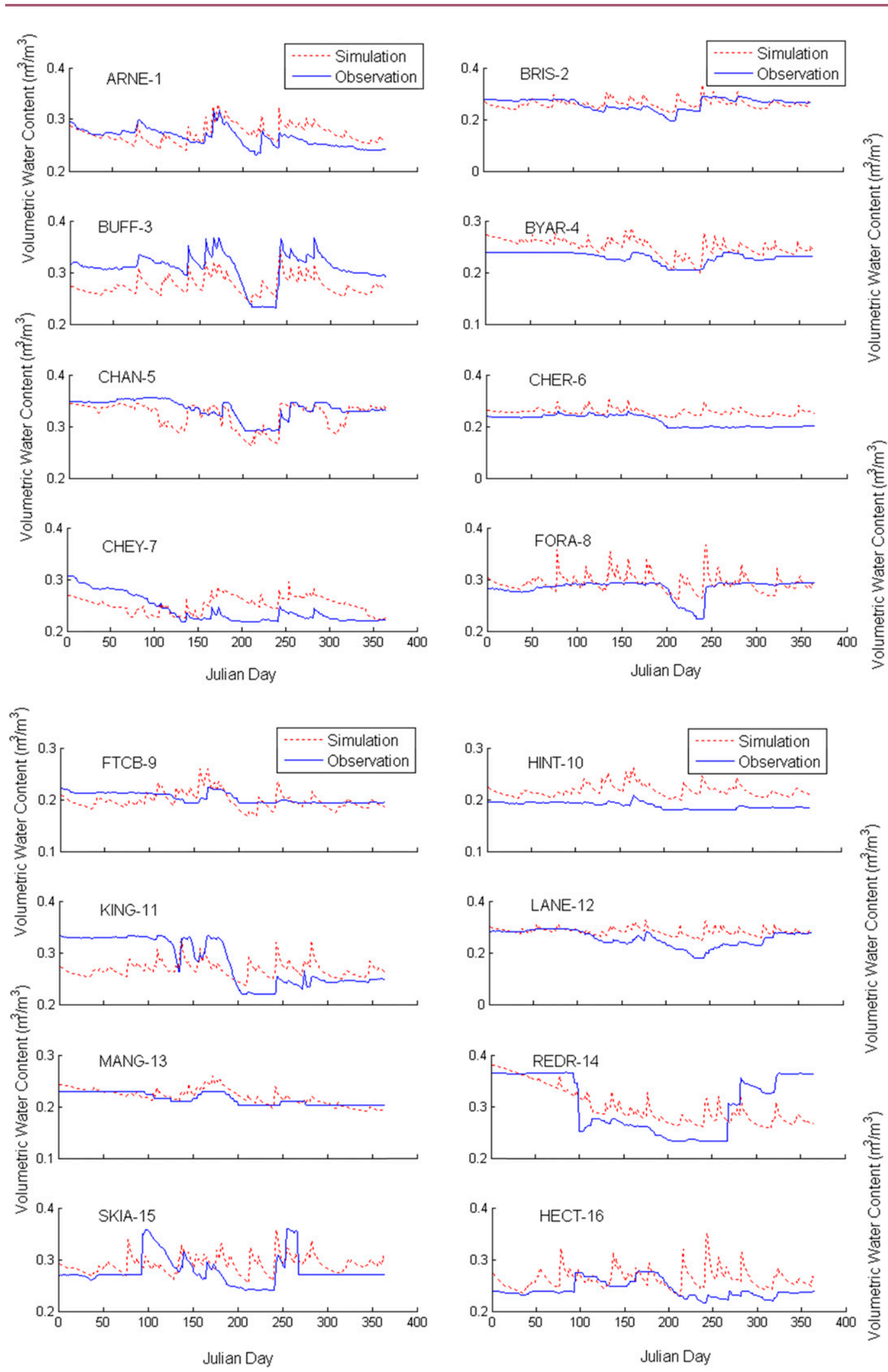

Figure 7. Simulated vs observed RZSM content $\left(\mathrm{m}^{3} \mathrm{~m}^{-3}\right)$ in 2003 at each Oklahoma Mesonet site. 
Earth Interactions - Volume 22 (2018) • Paper No. 15 • Page 15

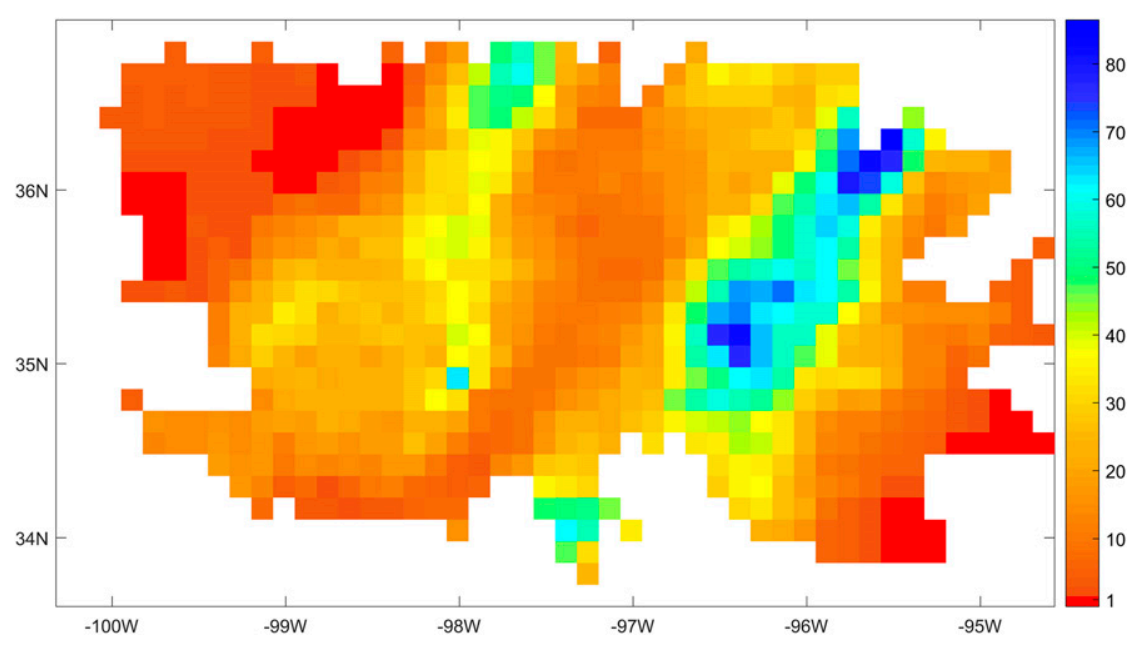

Figure 8. The total precipitation (mm) from NLDAS on 31 Aug 2003.

behavior of Mosaic is similar to Noah, but differs significantly from VIC. For TOPLATS, its behavior is similar to VIC. No models here could be treated as the reference for truth; thus, according to the VIC model, which provides relative reliable results among NLDAS models (Xia et al. 2012), TOPLATS performs well.

This study also assesses the model performance at local scale through comparing the simulated and observed RZSM temporal variations at 16 observation sites. The comparison results suggest that TOPLATS has good performance at local scales. However, the observed RZSM does not always fluctuate significantly in correspondence to the times when the simulated RZSM has a significant fluctuation. One possible reason is that the finer interpolated precipitation obtained is based on the precipitation with $0.125^{\circ}$ from NLDAS. In fact, the site within the 30 -arc-s grid may have very little or no precipitation, compared to the corresponding interpolated value, and that leads to the much-reduced fluctuation of observed RZSM. However, the interpolated value may be big and may lead to the much stronger fluctuation of simulated RZSM.

TI is one primary factor that affects RZSM distribution, but it is not the only one. Beven (1986) suggests that the larger values of TI correspond to the smaller slope of soil surface, where more soil moisture content can be found, but the rule does not apply in two areas where elevation and runoff patterns diverge. For example, the lowest TI exists in the southeastern study area, but RZSM content is not the lowest there. This suggests that TI can only be considered the one major influencing factor for RZSM distribution over certain areas, but it is not the only one. For different areas (e.g., upstream and downstream areas), other factors like elevation, runoff, vegetation, and precipitation can significantly affect the spatial variation of RZSM distribution.

\section{Conclusions}

The objective of this study is to evaluate whether TOPLATS has good performance in estimating finer-scale (e.g., 30 arc s) RZSM distribution based on coarse 
Earth Interactions - Volume 22 (2018) • Paper No. 15 • Page 16

(e.g., $0.125^{\circ}$ ) meteorological forcing data. Based on the results and discussions, we conclude the following.

TOPLATS can be considered to have good performance for estimating finerscale RZSM distribution through comparing the RZSM results from NLDAS. The performance of TOPLATS is high with respect to VIC, but not to Mosaic or Noah.

TI is one major influencing factor for RZSM distribution, but not the only one. Generally, the smaller TI relates to smaller RZSM, as if all other conditions (e.g., climate, soil, and vegetation) are the same; smaller values of TI correspond to areas with larger slope, where surface runoff and subsurface lateral flow are more easily generated, which can lead to smaller RZSM values. On top of that, variations in soil properties and vegetation type will certainly affect soil moisture distribution.

The direct comparison between the simulated and observed RZSM at the 16 sites may not be ideal since they are at different spatial scales. Other studies, such as Robock et al. (2003) and Xia et al. (2015), have used the average of multiple sites. The model runs at a much higher spatial resolution, which can reduce the scale difference to some extent. Future studies can improve this by using local meteorological forcing and site-specific soil and vegetation information.

Overall, the TOPLATS model performs well to a certain extent, and it can be used to estimate high-resolution RZSM.

Acknowledgements. This study was supported by NASA (Grant NNX13AI44G); the National Key R\&D Program of China (Grants 2016YFC0402706 and 2016YFC0402710); the National Natural Science Foundation of China (Grants 51709046, 41323001, 41130638, and 51539003); National Science Funds for Creative Research Groups of China (51421006); the program of Dual Innovative Talents Plan and Innovative Research Team in Jiangsu Province; the Open Foundation of State Key Laboratory of Cryospheric Science, Northwest Institute of Eco-Environment and Resources, Chinese Academy of Sciences (SKLCS-OP-2018-03); the Open Foundation of State Key Laboratory of Hydrology-Water Resources and Hydraulic Engineering, Hohai University (Grant 2015490311); and the Research Foundation for Talented Scholars of Fuzhou University (XRC-1553). Data provided by NCAR/EOL under sponsorship of the National Science Foundation. Oklahoma Mesonet data are provided courtesy of the Oklahoma Mesonet, which is jointly operated by Oklahoma State University and the University of Oklahoma. Continued funding for maintenance of the network is provided by the taxpayers of Oklahoma.

\section{References}

Al-Hamdan, O. Z., and J. F. Cruise, 2010: Soil moisture profile development from surface observations by principle of maximum entropy. J. Hydrol. Eng., 15, 327-337, https://doi.org/ 10.1061/(ASCE)HE.1943-5584.0000196.

Beven, K. J., 1986: Runoff production and flood frequency in catchments of order n: An alternative approach. Scale Problems in Hydrology, V. K. Gupta, I. Rodríguez-Iturbe, and E. F. Wood, Eds., Water Science and Technology Library Series, Vol. 6, Springer, 107-131, https://doi.org/ 10.1007/978-94-009-4678-1_6.

— hydrology. Hydrol. Sci. Bull., 24, 43-69, https://doi.org/10.1080/02626667909491834.

- and E. F. Wood, 1983: Catchment geomorphology and the dynamics of runoff contributing areas. J. Hydrol., 65, 139-158, https://doi.org/10.1016/0022-1694(83)90214-7. 
Earth Interactions - Volume 22 (2018) • Paper No. 15 • Page 17

_ _ M. J. Kirkby, N. Schofield, and A. F. Tagg, 1984: Testing a physically-based flood forecasting model (TOPMODEL) for three U.K. catchments. J. Hydrol., 69, 119-143, https://doi.org/ 10.1016/0022-1694(84)90159-8.

Beyene, T., D. P. Lettenmaier, and P. Kabat, 2010: Hydrologic impacts of climate change on the Nile River Basin: Implications of the 2007 IPCC scenarios. Climatic Change, 100, 433-461, https://doi.org/10.1007/s10584-009-9693-0.

Bindlish, R., T. Jackson, E. Wood, H. Gao, P. Starks, D. Bosch, and V. Lakshmi, 2003: Soil moisture estimates from TRMM Microwave Imager observations over the southern United States. Remote Sens. Environ., 85, 507-515, https://doi.org/10.1016/S0034-4257(03)00052-X.

Cheng, C. T., C. P. Ou, and K. W. Chau, 2002: Combining a fuzzy optimal model with a genetic algorithm to solve multi-objective rainfall-runoff model calibration. J. Hydrol., 268, 72-86, https://doi.org/10.1016/S0022-1694(02)00122-1.

Cosgrove, B. A., and Coauthors, 2003: Land surface model spin-up behavior in the North American Land Data Assimilation System (NLDAS). J. Geophys. Res., 108, 8845, https://doi.org/ 10.1029/2002JD003316.

Cuo, L., T. K. Beyene, N. Voisin, F. Su, D. P. Lettenmaier, M. Alberti, and J. E. Richey, 2011: Effects of mid-twenty-first century climate and land cover change on the hydrology of the Puget Sound basin, Washington. Hydrol. Processes, 25, 1729-1753, https://doi.org/10.1002/hyp.7932.

Daly, E., and A. Porporato, 2005: A review of soil moisture dynamics: From rainfall infiltration to ecosystem response. Environ. Eng. Sci., 22 (1), 9-24, https://doi.org/10.1089/ees.2005.22.9.

Dickinson, R. E., A. Henderson-Sellers, and P. J. Kennedy, 1993: Biosphere-Atmosphere Transfer Scheme (BATS) version 1e as coupled to the NCAR Community Climate Model. NCAR Tech. Note NCAR/TN-387+STR, 80 pp., https://doi.org/10.5065/D67W6959.

Entekhabi, D., and Coauthors, 2010: The Soil Moisture Active Passive (SMAP) mission. Proc. IEEE, 98, 704-716, https://doi.org/10.1109/JPROC.2010.2043918.

Esralew, R. A., and J. M. Lewis, 2010: Trends in base flow, total flow, and base-flow index of selected streams in and near Oklahoma through 2008. USGS Scientific Investigations Rep. 2010-5104, 143 pp., https://pubs.er.usgs.gov/publication/sir20105104.

Famiglietti, J. S., 1992: Aggregation and scaling of spatially-variable hydrological processes: Local, catchment-scale and macroscale models of water and energy balance. Ph.D. dissertation, Princeton University, 207 pp.

_ , and E. F. Wood, 1994a: Multiscale modeling of spatially variable water and energy balance process. Water Resour. Res., 30, 3061-3078, https://doi.org/10.1029/94WR01498.

$\ldots$, and - 1994b: Application of multiscale water and energy balance models on a tallgrass prairie. Water Resour. Res., 30, 3079-3093, https://doi.org/10.1029/94WR01499.

$\longrightarrow$, and _ 1995: Effects of spatial variability and scale on areally averaged evapotranspiration. Water Resour. Res., 31, 699-712, https://doi.org/10.1029/94WR02820.

$\mathrm{Fu}, \mathrm{X}$., and Coauthors, 2014: Investigating soil moisture sensitivity to precipitation and evapotranspiration errors using $\mathrm{SiB} 2$ model and ensemble Kalman filter. Stochastic Environ. Res. Risk Assess., 28, 681-693, https://doi.org/10.1007/s00477-013-0781-3.

Hanson, J. D., L. R. Ahuja, M. D. Shaffer, K. W. Rojas, D. G. DeCoursey, H. Farahani, and K. Johnson, 1998: RZWQM: Simulating the effects of management on water quality and crop production. Agric. Syst., 57, 161-195, https://doi.org/10.1016/S0308-521X(98)00002-X.

Heathman, G. C., P. J. Starks, L. R. Ahuja, and T. J. Jackson, 2003: Assimilation of surface soil moisture to estimate profile soil water content. J. Hydrol., 279, 1-17, https://doi.org/10.1016/ S0022-1694(03)00088-X.

Jayawardena, A. W., and M. C. Zhou, 2000: A modified spatial soil moisture storage capacity distribution curve for the Xinanjiang model. J. Hydrol., 227, 93-113, https://doi.org/10.1016/ S0022-1694(99)00173-0.

Ju, Q., Z. Yu, Z. Hao, G. Ou, J. Zhao, and D. Liu, 2009: Division-based rainfall-runoff simulations with BP neural networks and Xinanjiang model. Neurocomputing, 72, 2873-2883, https:// doi.org/10.1016/j.neucom.2008.12.032. 
Earth Interactions • Volume 22 (2018) • Paper No. 15 • Page 18

Kerr, Y. H., and Coauthors, 2010: The SMOS mission: New tool for monitoring key elements of the global water cycle. Proc. IEEE, 98, 666-687, https://doi.org/10.1109/JPROC.2010.2043032.

Kirkby, M. J., 1976: Hydrograph modelling strategies. Processes in Physical and Human Geography, R. Peel, M. Chisholm, and P. Haggett, Eds., Academic Press, 69-90.

Koster, R. D., M. J. Suarez, R. W. Higgins, and H. M. van den Dool, 2003: Observational evidence that soil moisture variations affect precipitation. Geophys. Res. Lett., 30, 1241, https://doi.org/ $10.1029 / 2002$ GL016571.

_ - and Coauthors, 2004: Regions of strong coupling between soil moisture and precipitation. Science, 305, 1138-1140, https://doi.org/10.1126/science.1100217.

Lettenmaier, D. P., D. Alsdorf, J. Dozier, G. J. Huffman, M. Pan, and E. F. Wood, 2015: Inroads of remote sensing into hydrologic science during the WRR era. Water Resour. Res., 51, 73097342, https://doi.org/10.1002/2015WR017616.

Li, F., W. T. Crow, and W. P. Kustas, 2010: Towards the estimation root-zone soil moisture via the simultaneous assimilation of thermal and microwave soil moisture retrievals. Adv. Water Resour., 33, 201-214, https://doi.org/10.1016/j.advwatres.2009.11.007.

Li, H., Y. Zhang, F. H. S. Chiew, and S. Xu, 2009: Predicting runoff in ungauged catchments by using Xinanjiang model with MODIS leaf area index. J. Hydrol., 370, 155-162, https:// doi.org/10.1016/j.jhydrol.2009.03.003.

Liang, X., D. P. Lettenmaier, E. F. Wood, and S. J. Burges, 1994: A simple hydrologically based model of land surface water and energy fluxes for general circulation models. J. Geophys. Res., 99, 14 415-14 428, https://doi.org/10.1029/94JD00483.

_ E. E. F. Wood, and D. P. Lettenmaier, 1996: Surface soil moisture parameterization of the VIC2L model: Evaluation and modification. Global Planet. Change, 13, 195-206, https://doi.org/ 10.1016/0921-8181(95)00046-1.

Lü, H., Z. Yu, Y. Zhu, S. Drake, Z. Hao, and E. A. Sudicky, 2011a: Dual state-parameter estimation of root zone soil moisture by optimal parameter estimation and extended Kalman filter data assimilation. Adv. Water Resour., 34, 395-406, https://doi.org/10.1016/j.advwatres.2010.12.005.

$\longrightarrow,-$, R. Horton, Y. Zhu, Z. Wang, Z. Hao, and L. Xiang, 2011b: Multi-scale assimilation of root zone soil water predictions. Hydrol. Processes, 25, 3158-3172, https://doi.org/10.1002/hyp.8034.

Ma, L., H. D. Scott, M. D. Shaffer, and L. R. Ahuja, 1998: RZWQM simulations of water and nitrate movement in a manured tall fescue field. Soil Sci., 163, 259-270, https://doi.org/ 10.1097/00010694-199804000-00001.

Mishra, V., K. A. Cherkauer, and L. C. Bowling, 2010: Parameterization of lakes and wetlands for energy and water balance studies in the Great Lakes Region. J. Hydrometeor., 11, 1057-1082, https://doi.org/10.1175/2010JHM1207.1.

Mitchell, K. E., and Coauthors, 2004: The multi-institution North American Land Data Assimilation System (NLDAS): Utilizing multiple GCIP products and partners in a continental distributed hydrological modeling system. J. Geophys. Res., 109, D07S90, https://doi.org/ 10.1029/2003JD003823.

Ni-Meister, W., and H. Gao, 2011: Assessing the impacts of vegetation heterogeneity on energy fluxes and snowmelt in boreal forests. J. Plant Ecol., 4, 37-47, https://doi.org/10.1093/jpe/rtr004.

Njoku, E., T. Jackson, V. Lakshmi, T. Chan, and S. Nghiem, 2003: Soil moisture retrieval from AMSR-E. IEEE Trans. Geosci. Remote Sens., 41, 215-229, https://doi.org/10.1109/TGRS.2002.808243.

Pan, M., A. K. Sahoo, and E. F. Wood, 2014: Improving soil moisture retrievals from a physicallybased radiative transfer model. Remote Sens. Environ., 140, 130-140, https://doi.org/10.1016/ j.rse.2013.08.020.

Pauwels, V. R. N., and E. F. Wood, 1999: A soil-vegetation-atmosphere transfer scheme for the modeling of water and energy balance process in high latitudes: 2 . Application and validation. J. Geophys. Res., 104, 27 823-27 839, https://doi.org/10.1029/1999JD900004.

Peters-Lidard, C. D., M. S. Zion, and E. F. Wood, 1997: A soil-vegetation-atmosphere transfer scheme for modeling spatially variable water and energy balance process. J. Geophys. Res., 102, 4303-4324, https://doi.org/10.1029/96JD02948. 
Earth Interactions • Volume 22 (2018) • Paper No. 15 • Page 19

Qin, J., S. Liang, K. Yang, I. Kaihotsu, R. Liu, and T. Koike, 2009: Simultaneous estimation of both soil moisture and model parameters using particle filtering method through the assimilation of microwave signal. J. Geophys. Res., 114, D15103, https://doi.org/10.1029/2008JD011358.

Robock, A., and Coauthors, 2003: Evaluation of the North American Land Data Assimilation System over the southern Great Plains during the warm season. J. Geophys. Res., 108, 8846, https://doi.org/10.1029/2002JD003245.

Rodell, M., and Coauthors, 2004: The Global Land Data Assimilation System. Bull. Amer. Meteor. Soc., 85, 381-394, https://doi.org/10.1175/BAMS-85-3-381.

Sellers, P. J., Y. Mintz, Y. C. Sud, and A. Dalcher, 1986: A simple biosphere model (SIB) for use within general circulation models. J. Atmos. Sci., 43, 505-531, https://doi.org/10.1175/ 1520-0469(1986)043<0505:ASBMFU > 2.0.CO;2.

Shukla, S., A. C. Steinemann, and D. P. Lettenmaier, 2011: Drought monitoring for Washington State: Indicators and applications. J. Hydrometeor, 12, 66-83, https://doi.org/10.1175/ 2010JHM1307.1.

Silberstein, R. P., M. Sivapalan, and A. Wyllie, 1999: On the validation of a coupled water and energy balance model at small catchment scales. J. Hydrol., 220, 149-168, https://doi.org/ 10.1016/S0022-1694(99)00075-X.

Sivapalan, M., K. J. Beven, and E. F. Wood, 1987: On hydrologic similarity: 2. A scaled model of storm runoff production. Water Resour. Res., 23, 2266-2278, https://doi.org/10.1029/ WR023i012p02266.

Western, A. W., and G. Blöschl, 1999: On the spatial scaling of soil moisture. J. Hydrol., 217, 203224, https://doi.org/10.1016/S0022-1694(98)00232-7.

Wood, E. F., M. Sivapalan, and K. J. Beven, 1990: Similarity and scale in catchment storm response. Rev. Geophys., 28, 1-18, https://doi.org/10.1029/RG028i001p00001.

— , and Coauthors, 2011: Hyperresolution global land surface modeling: Meeting a grand challenge for monitoring Earth's terrestrial water. Water Resour. Res., 47, W05301, https:// doi.org/10.1029/2010WR010090.

Xia, Y., M. B. Ek, H. Wei, and J. Meng, 2012: Comparative analysis of relationships between NLDAS-2 forcings and model outputs. Hydrol. Processes, 26, 467-474, https://doi.org/ 10.1002/hyp.8240.

,-- Y. Wu, T. Ford, and S. M. Quiring, 2015: Comparison of NLDAS-2 simulated and NASMD observed daily soil moisture. Part I: Comparison and analysis. J. Hydrometeor., 16, 1962-1980, https://doi.org/10.1175/JHM-D-14-0096.1.

Yu, Z., and Coauthors, 2014: One-dimensional soil temperature simulation with Common Land Model by assimilating in situ observations and MODISLST with the ensemble particle filter. Water Resour. Res., 50, 6950-6965, https://doi.org/10.1002/2012WR013473.

Zhao, R. J., 1992: The Xinanjiang model applied in China. J. Hydrol., 135, 371-381, https://doi.org/ 10.1016/0022-1694(92)90096-E.

— , Y. L. Zhang, L. R. Fang, X. R. Liu, and Q. S. Zhang, 1980: The Xinanjiang model. Proc. Hydrological Forecasting Symp., Oxford, United Kingdom, IAHS, 351-356.

Zhu, Z., and Coauthors, 2013: Global data sets of vegetation leaf area index (LAI)3g and fraction of photosynthetically active radiation (FPAR)3g derived from global inventory modeling and mapping studies (GIMMS) normalized difference vegetation index (NVDI3g) for the period 1981 to 2011. Remote Sens., 5, 927-948, https://doi.org/10.3390/rs5020927.

Earth Interactions is published jointly by the American Meteorological Society, the American Geophysical Union, and the Association of American Geographers. For information regarding reuse of this content and general copyright information, consult the AMS Copyright Policy (www.ametsoc.org/PUBSReuseLicenses). 